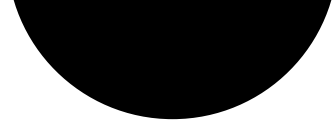

Correspondence should be sent to ip@rcpsych.ac.uk

\section{The impact of the uprising in Egypt on mental health in a private hospital}

Sir: After the recent uprising in Egypt, doctors expected a rise in the incidence of mental health disorders, especially cases of post-traumatic stress disorder (PTSD), but saw, surprisingly, a reduction in the number of admissions in the first few weeks. It is assumed that the curfew and the reduction in family income for many was behind this. Having said that, many other disorders - including organic mental disorders, such as traumatic brain injury, substance use disorders and subsequent drug-induced psychoses - seemed to have increased in incidence. Exacerbation of episodes of schizophrenia was also observed, with some of the persecutory delusions being related to surveillance by the police. Some patients had manic episodes that they correlated with the stress during the uprising. Depression and adjustment disorder were an expected occurrence. Bereavement reactions were observed not only over lost lives, but also among families of members of the old regime who were arrested.

There were logistical challenges as well. Shortages of medication became one of the difficulties that patients and doctors encountered. One new antidepressant's launch was postponed for a few months to accommodate the unrest. A local unit could not administer electroconvulsive therapy (ECT) owing to the erratic electrical supply and an ECT anaesthetist admitted to feeling exhausted because of the number of people that she treated elsewhere.

Early in the uprising, the curfew prevented some doctors from making it to work. Communication and access to information were a bit difficult without internet and mobile phones. Later, many doctors found themselves engaging in discussions with acutely ill patients who were asking for their rights to participate in parliamentary and later in presidential elections.

The uprising seems to have had both expected and unexpected consequences for mental health services and their users in the short term, and both time and a more systematic analysis will be required to ascertain the longer-term consequences.

\section{Emad Sidhom}

Registrar in Psychiatry, Behman Hospital, Cairo, Egypt (pre-Membership psychiatric trainee), email e.sidhom@gmail.com

\section{Report on drug and alcohol use in Iraq: the inaugural meeting of the Community Epidemiology Work Group}

Sir: The initial meeting of the Iraq Community Epidemiology Work Group (CEWG), 8-9 May 2012, held in Baghdad, brought together leaders and representatives from the public health and mental health sectors, law enforcement agencies, the universities, the governorates, nongovernmental organisations (NGOs) and the Ministries of Health, Interior, Labour and Social
Affairs, Youth and Sports, and Justice, as well as international technical assistance experts. The 2-day meeting reviewed the importance of and methods for developing a capacity in Iraq for better understanding the nature and extent of the drug and alcohol problem in the country and reviewed some of the existing data on this topic. Iraqi and international speakers provided background and a rationale for using the CEWG methodology as an optimal approach. Fourteen reports presented data on the current use of drugs and alcohol in Iraq. Ways of improving future CEWG meetings by expanding the types and sources of data were discussed in a workshop.

The findings from this meeting suggest that, since the reports by Aqrawi \& Humphreys (2009) and Al-Diwan (2011) on drug use in Iraq, summarised by Rawson (2011), some things have remained relatively stable, while there have been significant changes in other areas. The psychoactive substances most widely used in Iraq continue to be alcohol, benzodiazepines, benzhexol, codeine and a variety of psychiatric medications. This set of 'primary drugs' is consistent with the earlier reports. However, there was near universal agreement that the use of hashish, tramadol (an opioid-type analgesic) and amphetamine-type substances (ATS) is increasing rapidly in some areas and that drug and alcohol use overall is increasing. Reports from Basrah from health officials and police were noteworthy. Two types of ATS have made an appearance in Iraq: ' 01 pills' (tablets of captagon, an amphetamine-type drug) and 'crystal' (methamphetamine) have been seized in considerable quantities in Basrah. The 01 pills appear to be the same type of ATS that are being used in epidemic amounts in Saudi Arabia, and they appear to be coming into the country via the port of Basrah. 'Crystal' is likely coming from Iran, since drug seizures have been near the Iranian border and use of the drug in Iran is extensive. In addition, reports from Mosul and federal drug seizure data suggest that the use of tramadol is increasing substantially in many parts of Iraq. This drug is available to users from pharmacies and from street drug dealers. At present, there is little evidence of increased use of heroin in Iraq, and rates of injection drug use appear to continue to be relatively low.

The CEWG will continue to meet annually or more often to provide an ongoing monitoring programme regarding drug and alcohol use in Iraq.

\section{Nesif Al Hemiary MD, Jawad Al-Diwan MD PhD, Albert Hasson MSW and Richard A. Rawson PhD Iraq Community Epidemiology Work Group, email rrawson@ mednet.ucla.edu}

Al-Diwan, J. K. (2011) Alcohol and Substance Abuse in Baghdad 2010. Unpublished report.

Aqrawi, R. \& Humphreys, K. (2009) Responding to rising substance misuse in Iraq. Substance Use and Misuse, 44, 1744-1748.

Rawson, R. A. (2011) The Drug Situation in Iraq. Unpublished report. 